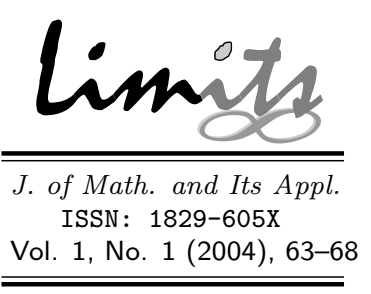

\title{
Model Matematika dan Analisanya Dari Pemenuhan Kebutuhan Air Bersih di Suatu Kompleks Perumahan
}

\author{
Basuki Widodo \\ Jurusan Matematika \\ Institut Teknologi Sepuluh Nopember, Surabaya \\ b_widodo@yahoo.com
}

\begin{abstract}
Abstrak
Air bersih merupakan kebutuhan manusia yang mendapatkan perhatian khusus untuk dipenuhi. Suatu kompleks perumahan tentu menginginkan tidak timbulnya masalah pada pemenuhan kebutuhan air bersihnya. Masalah yang sering dihadapi dalam pemenuhan kebutuhan air bersih adalah waktu pemenuhan yang kurang baik atau terlalu lama. Hal ini salah satunya dapat disebabkan oleh debit yang kurang optimal dari PDAM yang menuju kompleks perumahan tersebut, dan jumlah rumah yang terlalu banyak dalam kompleks perumahan tersebut. Karena itu perlu dibuatkan model matematikanya untuk menyelesaikan masalah tersebut. Didalam penelitian ini digunakan persamaan kontinuitas dan persamaan Bernoulli untuk pembuatan model matematika dari pemenuhan kebutuhan air bersih di suatu kompleks perumahan. Diperoleh hasil bahwa tekanan air berbanding terbalik dengan waktu pemenuhan.
\end{abstract}

Kata kunci: model matematika, air bersih, persamaan kontinuitas, persamaan Bernoulli

\section{Latar Belakang}

Air bersih merupakan salah satu kebutuhan masyarakat yang mendapatkan perhatian khusus untuk dipenuhi (Al-Layla, 1997). Masalah yang sering dihadapi dalam pemenuhan kebutuhan air bersih adalah waktu pemenuhan yang kurang baik atau terlalu lama. Hal ini dapat disebabkan oleh 2 hal, yaitu debit yang kurang optimal dari PDAM yang menuju kompleks perumahan tersebut dan jumlah rumah yang terlalu banyak dalam kompleks perumahan tersebut sehingga debit dari PDAM tidak akan memenuhi kebutuhan secara optimal.

Faktor-faktor penting yang mempengaruhi pemenuhan kebutuhan air bersih di suatu kompleks perumahan dapat disebabkan oleh 2 macam faktor. Pertama, disebabkan oleh debit pada pipa transmisi yang memang kecil sehingga tidak mencukupi untuk para pelanggan. Faktor kedua adalah disebabkan oleh keadaan aliran, yaitu aliran berubah-ubah karena faktor-faktor yang terjadi dalam pipa dan selama air mengalir dalam pipa tersebut.

\section{Permasalahan}

Permasalahan pada kajian ini adalah: Bagaimanakah model matematika dari masalah pemenuhan kebutuhan air untuk rumah tangga pada suatu kompleks perumahan dari sistem aliran PDAM? 


\section{Batasan Masalah}

Pada penelitian ini, batasan masalah yang digunakan adalah:

a. Pemakaian air hanya untuk kebutuhan rumah tangga dan sistem distribusi jaringan pipa primer, pipa sekunder dan pipa tersier digunakan Dead End System.

b. Hanya dibahas satu arah aliran air dan dimulai pada pipa primer dan pelanggan tidak menggunakan alat bantu, misalnya pompa air dan lain sebagainya.

c. Memperhitungkan kehilangan tenaga dan adanya faktor gesekan.

d. Diameter Pipa:

- Pipa primer $(\mathrm{Dp})=250 \mathrm{~mm}$

- Pipa sekunder (Ds) $=150 \mathrm{~mm}$

- Pipa tersier $(\mathrm{Dt})=20 \mathrm{~mm}$

e. Setiap percabangan pipa sekunder pada pipa primer $(\mathrm{Lp})$ adalah 30 meter dan percabangan pipa tersier pada pipa sekunder (Ls) adalah 12 meter.

f. Panjang pipa tersier (Lt) adalah 8 meter.

g. Sudut elevasi, yaitu kemiringan lahan terhadap pipa induk, sebesar $30^{\circ}$.

\section{Asumsi}

Diasumsikan dalam penelitian ini adalah bahwa:

a. Ketebalan pipa diabaikan.

b. Tidak terjadi kebocoran.

c. Air mengalir terus-menerus dan berhenti ketika kebutuhan air telah tercukupi.

d. Volume pemenuhan setiap rumah per hari konstan, yaitu $1,5 \mathrm{~m}^{3} /$ hari.

\section{Tujuan}

Tujuan yang ingin dicapai dalam penelitian ini adalah mencari model matematika dari masalah pemenuhan kebutuhan air bersih dan memprediksi jumlah pipa tersier, yaitu jumlah cabang pipa sekunder, untuk mendapatkan waktu pemenuhan yang optimal.

\section{Dasar Teori Dan Perumusan Model}

a. Sistem Distribusi Perpipaan Pipa Primer

Pipa primer adalah pipa yang mempunyai diameter relatif besar, yang fungsinya membawa air bersih dari instalasi pengolahan atau reservoir distribusi ke suatu kawasan (zona).

Pipa Sekunder (Arterial Main Pipe)

Pipa sekunder merupakan pipa yang mempunyai diameter lebih kecil dari pada pipa primer. Pipa sekunder disambung langsung pada pipa primer.

Pipa Tersier

Pipa tersier mempunyai diameter lebih kecil dari pipa sekunder dan dapat disambungkan langsung ke pipa sekunder, gunanya untuk melayani pipa service.

Pipa Service/Pemberi Air (Service Connection)

Pipa service mempunyai diameter yang relatif kecil. Pipa ini dapat disambungkan langsung pada pipa tersier yang dihubungkan kepada pelanggan.

b. Sistem Distribusi Aliran

Dead End System

Dead End System adalah sistem distribusi air dimana sebuah pipa utama ditempatkan pada jalan utama tegak lurus dengan jalan yang lebih kecil (pipa cabang) dan pipa cabang tersebut tidak saling berhubungan dengan bagian lain di akhir aliran, seperti pada Gambar 1.

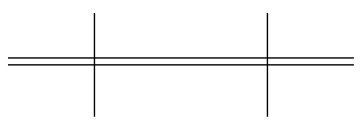

pipa sekunder pipa tersier

Gambar 1: Skema Sistem Distribusi Dead End

c. Gridiron System/Sistem Jejaring

Gridiron System adalah distribusi air dimana pipa cabang saling berhubungan satu sama lainnya.

\section{d. Sistem Pipa Pararel}

Sistem pipa pararel adalah kombinasi dua atau lebih pipa yang dihubungkan seperti 
pada Gambar 2. Dalam sistem pipa pararel harus dipenuhi kondisi sebagai berikut:

$$
Q=q_{1}+q_{2}+q_{3}
$$

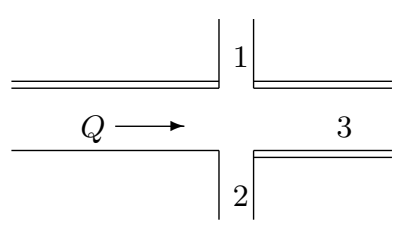

$\overline{ }$ pipa sekunder
pipa tersier

Gambar 2: Skema Sistem Pipa Paralel

\section{e. Aliran Air Melalui Pipa}

Faktor Gesekan

Menurut Wright dan Olson (1993), harga bilangan Reynolds yang diambil adalah Re $=40000$. Bilangan Reynold (Re) tersebut merupakan bilangan Reynolds kritis atas untuk aliran di dalam pipa dengan debit besar atau aliran turbulen. Harga faktor gesek $(f)$ aliran turbulen dengan bilangan Reynolds 40000 adalah 0,01.

Kehilangan Tenaga

Kehilangan tenaga yang terjadi pada pipa didefinisikan sebagai berikut:

- Kehilangan tenaga akibat perubahan diameter (dari besar ke kecil) dapat dihitung dengan persamaan:

$$
h_{f}=K_{c} \frac{v^{2}}{2}
$$

dengan $K_{c}=0,4\left(1-\frac{S_{b}}{S_{a}}\right)$ (Mc Cabe dan kawan-kawan, 1999).

- Kehilangan tenaga karena sambungan antar pipa (fitting) dapat dihitung dengan persamaan

$$
h_{f}=K_{f} \frac{v^{2}}{2}
$$

(Mc Cabe dan kawan-kawan, 1999).

Volume Pemenuhan Bak Tampung dan Debit

Volume pemenuhan bak tampung adalah jumlah kebutuhan air yang dibutuhkan suatu rumah tangga untuk suatu hari, yang dirumuskan sebagai

$$
V=Q t
$$

(Streeter dan Wylie, 1993). Debit aliran adalah jumlah (volume) aliran yang melalui suatu penampang persatuan waktu yang dirumuskan sebagai berikut:

$$
Q=V A
$$

Persamaan Bernoulli

Bentuk differensial persamaan Euler adalah

$$
\frac{d p}{\rho}+g d z+v d v
$$

Integrasi dari persamaan (6) adalah

$$
\frac{P}{\rho}+g Z+\frac{1}{2} v^{2}
$$

untuk suatu titik tertentu di dalam tabung atau pipa, umpamakan $\mathrm{O}$ dan O', persamaan (7) berbentuk

$$
\frac{P_{0}}{\rho}+g Z_{0}+\frac{1}{2} v_{0}^{2}=\frac{P_{0^{\prime}}}{\rho}+g Z_{0^{\prime}}+\frac{1}{2} v_{0^{\prime}}^{2}
$$

(White, 1988). Persamaan (8) merupakan persamaan Bernoulli untuk aliran takmampat tanpa gesekan. Pada aliran ini terjadi kehilangan tenaga dalam aliran fluida antara titik O dan O'. Persamaan (8) dapat ditulis

$$
\frac{P_{0}}{\rho}+g Z_{0}+\frac{1}{2} v_{0}^{2}=\frac{P_{0^{\prime}}}{\rho}+g Z_{0^{\prime}}+\frac{1}{2} v_{0^{\prime}}^{2}+h f
$$

(White, 1988).

\section{Persamaan Kontinuitas}

Massa fluida yang masuk dan meninggalkan tabung pada satu satuan waktu adalah

$$
m=\rho_{1} V_{1} A_{1}=\rho_{2} V_{2} A_{2}
$$

(Djojodiharjo, 1983). Jika debit $(Q)$ didefinisikan sebagai $Q=A V$, maka Persamaan (10) dapat berbentuk

$$
m=\rho_{1} Q_{1}=\rho_{2} Q_{2} .
$$

Untuk aliran tak-mampu mampat maka $\rho_{1}=\rho_{2}$, sehingga

$$
m=Q_{1}=Q_{2}
$$

\section{f. Persamaan Bernouli Pada Pipa} Sambungan Pipa Induk-Pipa Primer Pipa induk diasumsikan memiliki kemiringan $30^{\circ}$ terhadap lahan yang akan digunakan untuk membangun perumahan.

$$
\frac{P_{0}}{\rho}+g Z 0+\frac{1}{2} v_{0}^{2}=\frac{P_{0^{\prime}}}{\rho}+g Z_{0^{\prime}}+\frac{1}{2} v_{0^{\prime}}^{2}+h f
$$


$P_{0}$ merupakan tekanan awal berupa input dan diameter pipa tidak mengalami perubahan. Diantaranya belum terjadi percabangan. Pipa induk mengalami persambungan siku dengan pipa primer. Harga $K_{f}$ untuk persambungan siku tersebut adalah 0,9 sehingga

$$
\begin{gathered}
Q_{0}=Q_{0^{\prime}} \\
A p V_{0}=A p V_{0^{\prime}} \\
V_{0}=V_{0^{\prime}} \\
h f=\frac{v_{0^{\prime}}^{2}}{2}\left(4 f \frac{Z_{0^{\prime}} / \sin \theta}{D p}\right)+K_{f} \frac{1}{2} v_{0^{\prime}}^{2} \\
=\frac{v_{0^{\prime}}^{2}}{2}\left(4(0,001) \frac{2 / \sin 30^{\circ}}{0,25}\right)+(0,9) \frac{1}{2} v_{0^{\prime}}^{2} \\
=0,482 v_{0^{\prime}}^{2}
\end{gathered}
$$

(Nole de Nevers, 1991)

Persamaan (13) selanjutnya dapat ditulis

$$
P_{0^{\prime}}=\left[\frac{P_{0}}{1000}-2-0,0482 v_{0}^{2}\right] 1000
$$

Sambungan Pipa Induk - Pipa Primer Pada pipa primer diasumsikan dapat disambungkan 4 pipa sekunder.

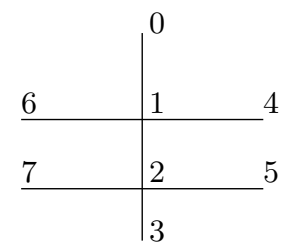

\section{Untuk titik 0-1}

$$
\begin{gathered}
\frac{P_{0}}{\rho}+g Z_{0}+\frac{1}{2} v_{0}^{2}=\frac{P_{1}}{\rho}+g Z_{1}+\frac{1}{2} v_{1}^{2}+h f \\
h f=\frac{v_{1}^{2}}{2}\left(4 f \frac{1 / 2 L p}{D P}\right)+K_{f} \frac{1}{2} v_{1}^{2} \\
=1,65 v_{0}^{2} \\
\frac{P_{0}}{\rho}+g Z_{0}+\frac{1}{2} v_{0}^{2}=\frac{P_{1}}{\rho}+g Z_{1}+\frac{1}{2} v_{1}^{2} \\
+\frac{v_{1}^{2}}{2}\left(4 f \frac{1 / 2 L p}{D P}\right)+K_{f} \frac{1}{2} v_{1}^{2}
\end{gathered}
$$

titik 0-1 mengalami percabangan siku di titik 1 dengan titik $1-4$ dan titik $1-6$. Diantara titik $0-1$ belum terjadi percabangan dan dipasang lurus horizontal sehingga $V_{0}=$ $V_{1}$ dan $Z_{0}=Z_{1}, P_{0}=P_{0^{\prime}}$.

$$
P_{1}=\left[\frac{P_{0^{\prime}}}{1000}-1,65 v_{0}^{2}\right] \cdot 1000
$$

\section{Untuk titik 1-4 dan titik 1-6}

Titik 1-4 dan titik 1-6 merupakan pipa sekunder sehingga diameter mengalami perubahan. Titik 1-4 dan 1-6 dipasang lurus horizontal $\left(Z_{1}=Z_{4} ; Z_{1}=Z_{6}\right)$.

$$
\begin{aligned}
& \frac{P_{1}}{\rho}+g Z_{1}+\frac{1}{2} v_{1}^{2}=\frac{P_{4}}{\rho}+g Z_{4}+\frac{1}{2} v_{4}^{2} \\
& +\frac{v_{4}^{2}}{2}\left(4 f \frac{1 / 2 L s}{D s}\right)+K_{C 1} \frac{1}{2} v_{4}^{2} \\
& K_{C 1}=0,4\left(1-\frac{D s^{2}}{D p^{2}}\right)=0,256 \\
& Q_{0}=Q_{4}+Q_{6}+Q_{2} \\
& Q_{2}=Q_{5}+Q_{7}+Q_{3} \\
& \text { Asumsi } \\
& Q_{4}=Q_{6}=20 \% Q_{0} \\
& Q_{5}=Q_{7}=10 \% Q_{0} \\
& Q_{2}=0,6 Q_{0} \\
& Q_{3}=0,4 Q_{0} \\
& Q_{4}=0,2 Q_{0} \\
& \text { As } v_{4}=0,2 Q_{0} \\
& (0,25) \pi D s^{2} v_{4}=0,2 Q_{0} \\
& (0,25) \pi(0,15)^{2} v_{4}=0,2 Q_{0} \\
& v_{4}=\frac{0,2 Q_{0}}{0,0176625} \\
& \begin{aligned}
P_{6}=P_{4}= & \frac{P_{1}}{1000}+0,5 v_{0}^{2} \\
& -1,428\left(\frac{0,2 Q_{0}}{0,0176625}\right) \cdot 1000
\end{aligned}
\end{aligned}
$$

\section{Untuk titik 1-2}

$$
\begin{aligned}
& \frac{P_{1}}{\rho}+g Z_{1}+\frac{1}{2} v_{1}^{2}=\frac{P_{2}}{\rho}+g Z_{2}+\frac{1}{2} v_{2}^{2} \\
& \quad+\frac{v_{2}^{2}}{2}\left(4 f \frac{1 / 2 L s}{D s}\right)+K_{f} \frac{1}{2} v_{2}^{2} \\
& Q_{2}=0,6 Q_{0} \\
& A p v_{2}=0,6 Q_{0} \\
& v_{2}=\frac{0,6 Q_{0}}{0,0490625}
\end{aligned}
$$

$Q_{2}=0,6 Q_{0}$

$P_{2}=$

$$
\left[\frac{P_{1}}{1000}+\frac{v_{0}^{2}}{2}-2.15\left(\frac{0,6 Q_{0}}{0,0490625}\right)\right] 1000
$$




\section{Untuk titik 2-5 dan titik 2-7}

$$
\begin{array}{r}
\frac{P_{2}}{\rho}+g Z_{2}+\frac{1}{2} v_{1}^{2}=\frac{P_{4}}{\rho}+g Z_{4}+\frac{1}{2} v_{5}^{2} \\
+\frac{v_{5}^{2}}{2}\left(4 f \frac{1 / 2 L s}{D s}\right)+K_{C 1} \frac{1}{2} v_{5}^{2}
\end{array}
$$

$$
\begin{aligned}
& K_{C 1}=0,256 \\
& Z_{2}=Z_{5} \\
& Z_{2}=Z_{7} \\
& P_{5}=\left[\frac{P_{2}}{1000}+\frac{v_{2}^{2}}{2}-1,428 v_{5}^{2}\right] 1000 \\
& Q_{5}=0,1 Q_{0} \\
& \text { As } v_{5}=0,1 Q_{0} \\
& (0,25) \pi D s^{2} v_{5}=(0,1) Q_{0} \\
& (0,25) \pi(0,15)^{2} v_{5}=(0,1) Q_{0} \\
& v_{5}=\frac{(0,1) Q_{0}}{0,0176625} \\
& \quad P_{7}=P_{5}=\left[\frac{P_{2}}{1000}+\frac{1}{2}\left(\frac{0,6 Q_{0}}{0,0490625}\right)^{2}\right. \\
& \left.\quad-1,428\left(\frac{0,1 Q_{0}}{0,0176625}\right)^{2}\right] 1000
\end{aligned}
$$

\section{Untuk titik 2-3}

$$
\begin{aligned}
& \frac{P_{2}}{\rho}+g Z_{2}+\frac{1}{2} v_{2}^{2}=\frac{P_{3}}{\rho}+g Z_{3}+\frac{1}{2} v_{3}^{2} \\
& +\frac{v_{3}^{2}}{2}\left(4 f \frac{1 / 2 L s}{D s}\right)+K_{f} \frac{1}{2} v_{3}^{2} \\
& Q_{3}=(0,4) Q_{0} \\
& A p v_{3}=(0,4) Q_{0} \\
& (0,25) \pi(0,25)^{2} v_{3}=(0,4) Q_{0} \\
& v 3=\frac{0,4 Q_{0}}{0,0490625} \\
& P_{3}=\left[\frac{P_{3}}{1000}+\frac{1}{2}\left(\frac{0,6 Q_{0}}{0,0490625}\right)^{2}\right. \\
& \left.-2,15\left(\frac{0,4 Q_{0}}{0,0490625}\right)^{2}\right] 1000
\end{aligned}
$$

\section{Sambungan Pipa Sekunder - Pipa Ter-} sier

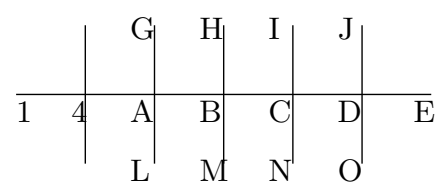

\section{Untuk titik 4-F}

$$
\begin{aligned}
\frac{P_{4}}{\rho}+g Z_{4}+\frac{1}{2} v_{4}^{2}=\frac{P_{F}}{\rho}+g Z_{F}+\frac{1}{2} v_{F}^{2} \\
+\frac{v_{F}^{2}}{2}\left(4 f \frac{1 / 2 L t}{D t}\right)+K_{C 2} \frac{1}{2} v_{F}^{2} \\
K_{C 2}=0,4\left(1-\frac{D t^{2}}{D s^{2}}\right)=0,0393 \\
v_{F}=\sqrt{\frac{2\left(\frac{P_{4}}{\rho}+\frac{1}{2} v_{4}^{2}\right)}{1+\left(4 f \frac{L t}{D t}\right)+K_{C 2}}} \\
=\sqrt{\frac{2\left[\frac{P_{4}}{1000}+\frac{1}{2}\left(\frac{0,2 Q_{0}}{0,0176625}\right)^{2}\right]}{1+\left(4(0,01) \frac{8}{0,02}\right)+0,393}} \\
v_{K}=\sqrt[v_{F}]{\frac{2\left[\frac{P_{4}}{1000}+\frac{1}{2}\left(\frac{0,2 Q_{0}}{0,0176625}\right)^{2}\right]}{17,393}}
\end{aligned}
$$

\section{Untuk titik 4-A}

$$
\begin{array}{r}
\frac{P_{4}}{\rho}+g Z_{4}+\frac{1}{2} v_{4}^{2}=\frac{P_{A}}{\rho}+g Z_{A}+\frac{1}{2} v_{A}^{2} \\
+\frac{v_{A}^{2}}{2}\left(4 f \frac{1 / 2 L s}{D s}\right)+K_{f} \frac{1}{2} v_{A}^{2}
\end{array}
$$

$Z_{4}=Z_{A}$

Sesuai dengan sistem pipa pararel $Q_{4}=Q_{F}+Q_{K}+Q_{A}$

$$
\begin{gathered}
\text { As } v_{4}=A t v_{F}+A t v_{K}+A s v_{A} \\
v_{A}=\frac{(0,15)^{2} v_{4}-(0,02)^{2} v_{F}-(0,02)^{2} v_{K}}{(0,15)^{2}} \\
P_{A}=\left[\frac{P_{4}}{1000}+\frac{1}{2}\left(\frac{0,2 Q_{0}}{0,0176625}\right)^{2}\right. \\
\left.-1,75 v_{A}^{2}\right] \cdot 1000
\end{gathered}
$$

Untuk titik $\mathrm{A}-\mathrm{G}$ dan seterusnya dilakukan perlakuan yang sama dalam mendapatkan persamaan. 


\section{Hasil dan Pembahasan}

Pada Cabang Pipa Primer (titik 1-4 dan titik 1-6)

Berdasarkan persamaan yang ada dapat diperoleh waktu pemenuhan kebutuhan air dan ditampilkan dalam bentuk grafik dibawah ini.

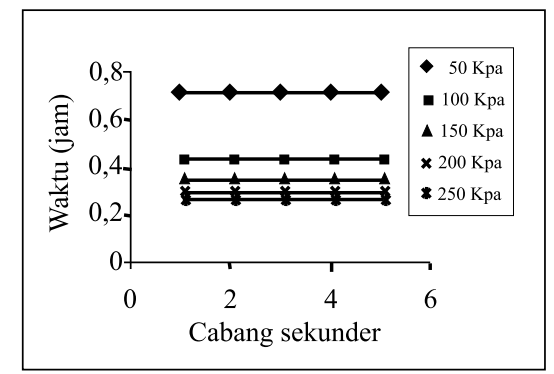

Gambar 1: Grafik Pemenuhan Kebutuhan Air Setiap Cabang Pipa Sekunder Untuk

$$
Q_{0}=100 \mathrm{~m}^{3} / \mathrm{jam} \text {. }
$$

Berdasarkan grafik diatas dapat dapat dijelaskan bahwa waktu pemenuhan air untuk jumlah cabang sekunder tidak terlalu banyak, yaitu sebanyak 5, relatif sama pada semua cabang sekunder namun waktu pemenuhan air akan berkurang dengan bertambahnya besar tekanan air dari PDAM.

\section{Kesimpulan}

Dari hasil penelitian yang telah dilakukan dapat disimpulkan bahwa tekanan air berbanding terbalik dengan waktu pemenuhan.

\section{Daftar Pustaka}

[1] Al-Layla, M.A., Water Supply Engineering Design, cetakan 4, Ann Arbor Science Publishers Inc, Singapore, 1997.

[2] Djojodiharjo, H., Mekanika Fluida, Departemen Mesin ITB, Erlangga, Jakarta, 1983.

[3] McCabe, W.L., Smith, J.C. dan Harriot, P., Operasi Teknik Kimia, jilid 1, edisi 4, Erlangga, Jakarta, 1999.
[4] Nole de Nevers, Fluid Mechanics for Chemical Engineers, 2nd edition, McGraw-Hill, Inc., Singapore, 1991.

[5] Streeter, V.I dan Wylie, E.B., Mekanika Fluida, . jilid 1 dan 2 (terjemahan), cetakan 4, Erlangga, Jakarta, 1993.

[6] White, F.M., Mekanika Fuida, jilid 1, edisi 2, Erlangga, Jakarta, 1988.

[7] Wright, S.J dan Olson, R.M., Dasar Dasar Mekanika Fluida Teknik, edisi 5 (terjemahan), Gramedia Pustaka Utama, Jakarta, 1993.

\section{Daftar Notasi}

$h_{f}$ : kehilangan tenaga akibat perubahan diameter pipa

$K_{c}$ : koefisien kehilangan energi utama

$v$ : kecepatan air di permukaan meter/detik

$S_{a}$ : luas penampang area pipa kecil

$S_{b}$ : luas penampang area pipa besar

$K_{f}$ : koefisien kehilangan tenaga karena sambungan antar pipa

$V$ : kecepatan rata-rata air dalam pipa, meter $^{3} /$ detik

$Q$ : debit air (mass flowrate), meter $^{3} / \operatorname{detik}$

$t$ : waktu, detik

$A$ : luas penampang pipa, meter ${ }^{2}$

$P$ : tekanan, Pascal $(\mathrm{Pa})$

$\rho \quad$ : densitas air, $\mathrm{kg} /$ meter $^{3}$

$g$ : gaya gravitasi bumi, meter $/ \operatorname{detik}^{2}$

$Z$ : ketinggian pipa terhadap pipa induk, meter

$m$ : massa air, $\mathrm{kg}$

$f$ : faktor gesekan terhadap dinding pipa

$\theta$ : sudut kemiringan pipa terhadap pipa induk, radian

$D p$ : diameter penampang pipa primer, meter

$L p$ : panjang pipa primer, meter

$D s$ : diameter penampang pipa sekunder, meter

$L s$ : panjang pipa sekunder, meter

$D t$ : diameter penampang pipa tersier, meter

$L t$ : panjang pipa tersier, meter

$R e$ : bilangan Reynold 